\title{
Movements and Activity Budgets of Caribou Near Oil Drilling Sites in the Sagavanirktok River Floodplain, Alaska
}

\author{
STEVE G. FANCY'
}

\begin{abstract}
Movements and activity patterns were compared for caribou (Rangifer tarandus granti) near two active drilling sites on the periphery of the Prudhoe Bay oilfield and for caribou from a control site. Caribou on the experimental and control sites had similar movement rates and activity budgets, but many localized responses to the roads, pipelines, vehicle traffic, and other structures and activities were observed. Insect harassment had an appreciable effect on caribou movements and activity budgets. Groups harassed by insects moved approximately twice as fast and spent at least $50 \%$ less time lying and feeding than did unharassed groups. Of the 99 groups that approached a road, pipeline, and/or drill site, $70.7 \%$ crossed directly, $19.2 \%$ detoured around the drill site, and $10.1 \%$ reversed direction and left the study area. No evidence was found that caribou cows and calves were avoiding the area because of drilling operations.
\end{abstract}

Key words: caribou, Rangifer tarandus granti, movements, disturbance, insect harassment, Prudhoe Bay, petroleum development

RÉSUMÉ. Les mouvements et activités du caribou (Rangifer tarandus granti) sont comparés près de deux sites de forage actif dans la périphérie du champ de pétrole de la baie Prudhoe ainsi que dans un site de contrôle. Les caribous dans les sites expérimentaux et de contrôle présentaient un taux de mouvement et un régime d'activité semblables, mais on observa un bon nombre de réactions localisées aux routes, aux pipelines, à la circulation de véhicules et à d'autres structures et activités. Les tourments infligés par les insectes ont eu un effet appréciable sur les mouvements et le régime d'activité. Les groupes tourmentés par les insectes se déplaçaient environ deux fois plus vite que les groupes non tourmentés, et passaient environ $50 \%$ moins de temps à se nourrir et à se reposer que ces derniers. Des 99 groupes ayant approché une route, un pipeline et/ou un site de forage $70.7 \%$ traversaient directement, $19.2 \%$ faisaient un détour autour du site de forage, et $10.1 \%$ faisaient demi-tour et quittaient le champs d'étude. Aucune preuve $n$ 'a indiqué que les vaches et les veaux des caribous évitaient la région à cause des travaux de forage.

Mots clés: caribou, Rangifer tarandus granti, mouvements, perturbation, les tourments infligés par les insects, la baie Prudhoe, developpement de l'industrie pétrolifere

Traduit pour le journal par Maurice Guibord.

\section{INTRODUCTION}

Caribou (Rangifer tarandus granti) of the Central Arctic herd frequently encounter an expanding network of roads, pipelines, and drill pads on their calving grounds and summer range. The effects of these developments on caribou movements, activity budgets, and productivity have been the focus of much speculation, and in recent years, of intensive study. Early studies by Child (1974) demonstrated that pipelines elevated only $0.8 \mathrm{~m}$ above ground presented a barrier to caribou movements. Current permit stipulations require newly constructed pipelines on Alaska's North Slope to be elevated at least $1.5 \mathrm{~m}$ or buried. The experiments of Child (1974), while providing much-needed data for the design of the TransAlaska pipeline, used simulated pipelines of snow fencing and culverting that were elevated to heights not usually encountered by Central Arctic caribou. Cameron and Whitten $(1979,1980)$ and Cameron et al. (1979) have studied the effects of the Prudhoe Bay oilfield and the Trans-Alaska pipeline corridor on caribou since 1974. Their studies suggest an avoidance of the corridor and oilfield by cows in late pregnancy and cows with young calves, based on a lower percentage of calves in caribou groups observed from roads as compared to aerial sightings over a large area.

This study was initiated to determine if the movements and activities of caribou were significantly altered by the presence of drilling structures (e.g., roads, pipelines, drill pads, buildings) and human activities (e.g., vehicle traffic, presence of workers) in the Sagavanirktok River floodplain, an area commonly traversed by caribou during mosquito-induced movements to coastal areas. Because it was not possible to distinguish between the effects of roads, pipelines, gravel drilling-pads, vehicle traffic, drilling noise, and the presence of workers, I report here on the combined effects of these and other structures and human activities on caribou movements and activities.

\section{METHODS}

\section{Study Areas}

A $9-\mathrm{km}^{2}$ study area was established at drill sites 16 and 17 , located on the arctic coastal plain between the main and west channels of the lower Sagavanirktok River Delta (Fig. 1). The area is characterized by poorly-drained polygonal tundra dominated by low-lying grasses and sedges, with Dryas-heath meadows on drier sites. Raised gravel roads and pipelines, each elevated approximately $2 \mathrm{~m}$, connected each drill site to the oilfield road and pipeline network (Fig. 2). Drilling operations occurred at both drill sites throughout the study. The rate of vehicle traffic determined from one randomly-selected one- 


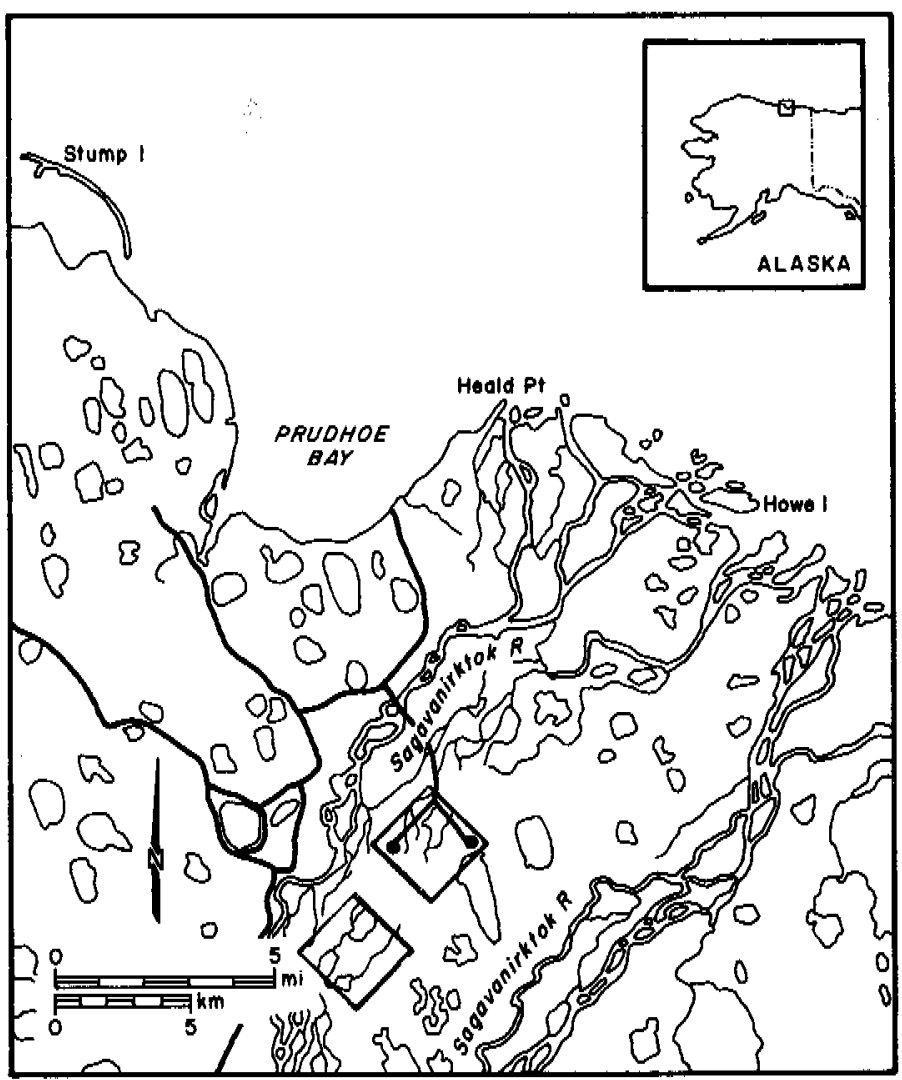

FIG. 1. Locations of drill sites 16 and 17 at Prudhoe Bay, Alaska. The outlined areas represent the locations of the drill site grid and the control grid.

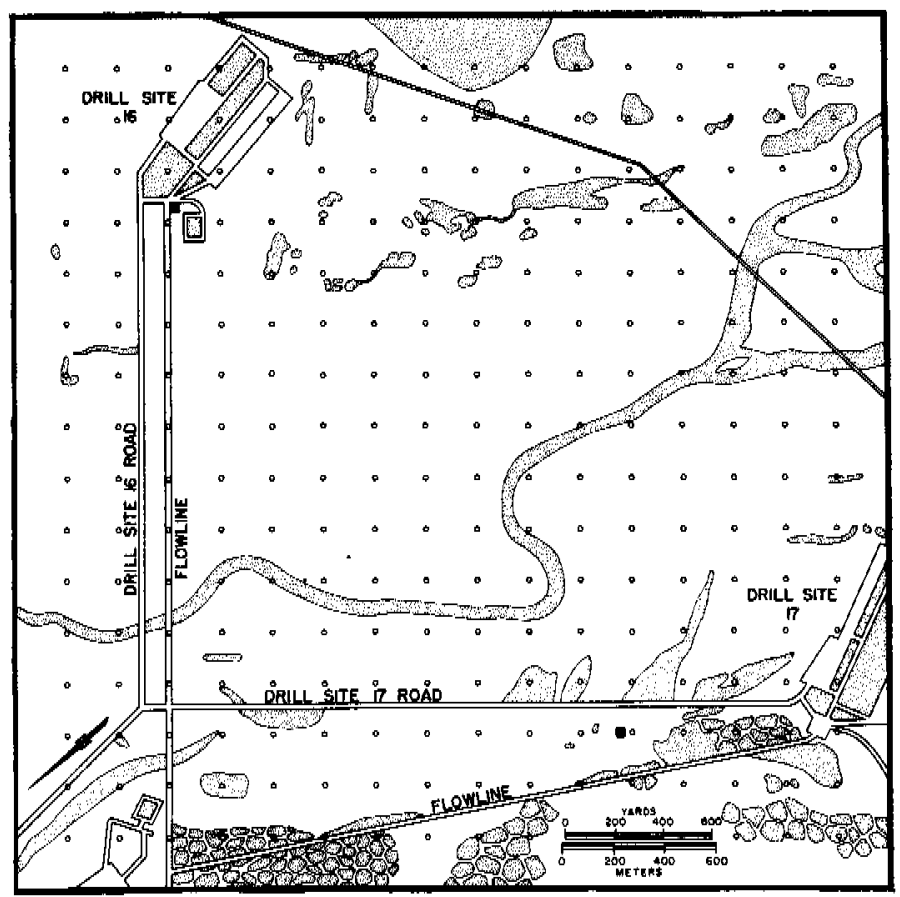

FIG. 2. Map of roads, drill pads, and flowlines at drill sites 16 and 17. Shaded areas represent ponds and streams on the study area. Locations of towers are represented by dark squares; open circles represent the grid markers. hour count each day averaged 12.5 round trips per hour. Color-coded grid markers were placed at 200-m intervals so that the location of caribou on the grid could be easily determined.

A $9-\mathrm{km}^{2}$ area centered approximately $4 \mathrm{~km}$ south of drill site 17 was similarly established for use as a control. Topography and vegetation were similar to the drill site study area. The nearest road was located across the west channel of the Sagavanirktok River, $4 \mathrm{~km}$ west of the grid center. Two abandoned winter roads (appearing in summer as unelevated gravel strips approximately $5 \mathrm{~m}$ wide) and an abandoned drill pad were located within the control site.

\section{Data Collection}

The movements and activities of caribou were recorded by direct observation between 1 July and 10 August 1981 . Observations on each grid were made simultaneously by two observers located in 4-m towers (see Fig. 2 for locations of towers on the drill site grid; towers on the control grid were placed in a similar configuration). Radios were used to communicate between towers. Observations were made between 0700 and 1700 (Alaska Daylight Time) each day, except when dense fog precluded observations. Data were recorded after $1700 \mathrm{~h}$ if any caribou remained on the grid at that time. Observers on the control grid often slept in the towers and made occasional observations at night. The location (determined by reference markers and estimated to the nearest $50 \mathrm{~m}$ ), activity (lying, standing, feeding, walking, running) and group composition of caribou on each grid were recorded at two-minute intervals using scan sampling (Altmann, 1974). A group was defined as one or more individuals each within $200 \mathrm{~m}$ of another and moving in the same general direction. Observations were recorded directly onto computer forms in the field and later transferred to a computer file.

\section{Data Analysis}

The distance a group traveled during each two-minute interval was used to calculate a rate of movement. A mean rate of movement for each group observed on the grid was calculated from these rates of movement. The number of individual caribou engaged in each activity category during each two-minute scan sample was used to calculate the proportion of time a group spent in each activity. For some groups (particularly large, slow-moving groups), the activity of each individual could not be recorded; in these cases only, the predominant group activity during each scan sample was recorded.

An insect harassment level (low or high) was determined for each group from the relationship between insect harassment and temperature/wind (White et al., 1975). The insect level for a group was considered high if the wind speed at $1 \mathrm{~m}$ above ground level (adjusted from hourly Deadhorse Airport weather records using the method of White et al., 1975) was less than that calculated from the equation:

$$
\text { WIND }=(0.9091 * \text { TEMP })+0.5454
$$

This equation describes the line separating the "none" insect harassment category from the moderate and severe categories 
of White et al. (1975). The insect level determined by this method generally agreed with the subjective levels based on the number of mosquitos visible through the tower windows and/or from the behavioral responses of caribou.

Because lying and feeding are associated with energy intake and/or a relaxed state, the proportion of time a group spent in these activities was used as an indicator of the disturbance due to local drilling operations. Analysis of covariance was used to compare the rate of movement, and proportion of time spent lying and feeding, between grids after the proportions were transformed using the arcsine square root transformation (Sokal and Rohlf, 1969). The proportion of calves in each group was used as a covariate because the presence of calves has been shown to influence group movement and activity (e.g., White et al., 1975; Roby, 1978). I used the proportion of calves rather than the presence or absence of calves in these analyses because a single cow/calf pair will presumably influence the behavior of a small group more than it will a large group. The effect of vehicle traffic is included in comparisons between the two grids, but is not otherwise controlled for. Traffic rates were relatively constant throughout the study and all groups were exposed to at least one moving vehicle while on the drill site grid. The distance at which the movements of caribou were influenced by vehicles appeared to be highly variable. Statistical significance was evaluated at the $95 \%$ confidence interval unless otherwise noted.

\section{RESULTS AND DISCUSSION}

\section{Rate of Movement}

In total, 1035 caribou were observed on the drill site grid as compared to 998 on the control grid (applies only to periods when both grids were monitored simultaneously). The mean rate of movement of groups on the drill site grid during both low and high insect levels was not significantly different from those of corresponding groups on the control grid (Table 1).

TABLE 1. Mean rate of movement $\left(\mathrm{km} \cdot \mathrm{h}^{-1}\right)$ of caribou groups on the drill site and control grids during periods of low and high insect harassment. The proportion of calves in a group has been used as a covariate.

\begin{tabular}{|c|c|c|c|c|c|c|}
\hline & \multicolumn{3}{|c|}{ LOW INSECTS } & \multicolumn{3}{|c|}{ HIGH INSECTS } \\
\hline & $n$ & Mean & S.E. & $\mathbf{n}$ & Mean & S.E. \\
\hline Drill Site Grid & 38 & 2.4 & 0.32 & 92 & 4.2 & $\overline{0.43}$ \\
\hline Control Grid & 122 & 2.1 & 0.18 & 58 & 5.4 & 0.54 \\
\hline \multicolumn{7}{|l|}{ Analysis of Covariance } \\
\hline $\begin{array}{l}\text { Equality of } \\
\text { Adjusted Means } \\
\text { Zero Slope' } \\
\text { Equality of Slopes? }\end{array}$ & \multicolumn{3}{|c|}{$\begin{array}{ll}F=0.78 & P>0.20 \\
F=0.17 & P>0.50 \\
F=0.18 & P>0.50\end{array}$} & \multicolumn{3}{|c|}{$\begin{array}{ll}F=2.72 & P>0.10 \\
F=0.28 & P>0.50 \\
F=0.09 & P>0.50\end{array}$} \\
\hline
\end{tabular}

'Test to determine if the proportion of calves in a group significantly affects its rate of movement

${ }^{2}$ Test to determine if the proportion of calves has the same effect on the rate of movement on both grids

No relationship was found between rate of group movement and the proportion of calves in a group for either level of insect activity. Other researchers (e.g., Child, 1974; White et al.,
1975; Roby, 1978) have used the presence or absence of calves rather than the proportion of calves in a group to evaluate the effects of calves on group movements. I therefore compared movement rates of groups with and without calves (both grids combined); the presence of calves had no effect on movement rates during either insect level (Table 2).

TABLE 2. Rate of movement $\left(\mathrm{km} \cdot \mathrm{h}^{-1}\right)$ and proportion of time spent lying and feeding by groups with and without calves (both grids combined). The activity means have been back-transformed to proportions.

\begin{tabular}{|c|c|c|c|c|c|c|}
\hline & \multicolumn{3}{|c|}{ LOW INSECTS } & \multicolumn{3}{|c|}{ HIGH INSECTS } \\
\hline & $\mathrm{n}$ & Mean & S.E. & n & Mean & S.E. \\
\hline \multicolumn{7}{|l|}{ Rate of Movement } \\
\hline With Calves & 32 & 13.3 & 0.6 & 45 & 9.2 & 0.4 \\
\hline Without Calves & 128 & 13.2 & 0.4 & 105 & 9.5 & 0.3 \\
\hline Analysis of Variance & \multicolumn{3}{|c|}{$F=0.01 \quad P>0.93$} & \multicolumn{3}{|c|}{$F=0.48 \quad P>0.48$} \\
\hline \multicolumn{7}{|c|}{ \% Time Lying and Feeding } \\
\hline With Calves & 32 & 0.55 & 3.3 & 45 & 0.31 & 3.6 \\
\hline Without Calves & 128 & 0.73 & 1.7 & 105 & 0.29 & 2.3 \\
\hline Analysis of Variance & \multicolumn{3}{|c|}{$F=8.50 \quad P<0.005$} & \multicolumn{3}{|c|}{$F=0.09 P>0.76$} \\
\hline
\end{tabular}

On both grids, groups harassed by mosquitos and/or oestrid flies moved significantly faster $(\mathrm{P}<0.001)$ than unharassed groups. Caribou made directed movements toward the coast when mosquitos were the predominant insect pest. In early August, when oestrid flies predominated, caribou movement had no clear orientation and movement rates of traveling caribou were higher than those calculated during mosquito harassment. One group of cows and calves in early August averaged $22 \mathrm{~km} \cdot \mathrm{h}^{-1}$ between two points $1 \mathrm{~km}$ apart.

The predominant direction of movement of caribou on both grids was NE, parallel to the river. Thus, most caribou crossed both the control and drill site grids. However, interchange of individuals among groups was common, and only 17 groups crossed both grids intact during similar insect conditions. The rate of movement on the drill site grid (mean $=4.6 \mathrm{~km} \cdot \mathrm{h}^{-1}$ ) for these 17 groups was less than that on the control grid (mean $\left.=7.5 \mathrm{~km} \cdot \mathrm{h}^{-1}\right)($ pairwise $\mathrm{t}$-test; $\mathrm{t}=2.46 ; \mathrm{P}<0.05$ ). Twelve of these 17 groups were harassed by insects, and thus the value calculated for the drill site grid $\left(4.6 \mathrm{~km} \cdot \mathrm{h}^{-1}\right)$ seerns reasonable based on the movement rates of all groups during high insect levels (Table 1). I have no adequate explanation for the higher rate of movement of these groups while crossing the control grid.

\section{Activity}

The proportion of time caribou spent lying and feeding on the drill site grid was not significantly different $(P>0.05)$ from that on the control grid during either low or high insect levels (Table 3). However, harassment by insects had a significant effect on activity on both grids (t-test; $P<0.001$ ). On the control grid, caribou under high levels of insect harassment spent only $34 \%$ of the time lying and feeding, as compared to $72 \%$ during low insect levels (Table 3). The proportion of time spent lying and feeding by the 17 groups that crossed both 
grids intact and under similar insect conditions was similar for the two grids (pairwise $t$-test; $t=0.29 ; P>0.50$ ). During high levels of insect abundance, the proportion of calves in a group was not significantly related to the proportion of time a group spent lying and feeding. During periods of low insect harassment, however, there was a significant inverse relationship on both grids between the proportion of calves in a group and the proportion of time spent lying and feeding (Table 3). The same relationships were found when the presence or absence of calves was used rather than the proportion of calves in a group (Table 2).

TABLE 3, Proportion of time groups spent. lying and feeding on the drill site and control grids during periods of low and high insect harassment. The proportion of calves in a group has been used as a covariate. The means have been back-transformed to proportions.

\begin{tabular}{|c|c|c|c|c|c|c|}
\hline & \multicolumn{3}{|c|}{ LOW INSECTS } & \multicolumn{3}{|c|}{ HIGH INSECTS } \\
\hline & n & Mean & S.E. & $n$ & Mean & S.E. \\
\hline Drill Site Grid & 38 & 0.62 & 3.10 & 92 & 0.27 & 2.48 \\
\hline Control Grid & 122 & 0.72 & 1.73 & 58 & 0.34 & 3.12 \\
\hline \multicolumn{7}{|l|}{ Analysis of Covariance } \\
\hline $\begin{array}{l}\text { Equality of } \\
\text { Adjusted Means } \\
\text { Zero Slope } \\
\text { Equality of Slopes }\end{array}$ & \multicolumn{3}{|c|}{$\begin{array}{ll}F=2.88 & P>0.09 \\
F=6.73 & P<0.05 \\
F=1.15 & P>0.20\end{array}$} & \multicolumn{3}{|c|}{$\begin{array}{ll}F=1.27 & P>0.20 \\
F=0.57 & P>0.40 \\
F=0.04 & P>0.80\end{array}$} \\
\hline
\end{tabular}

I observed numerous changes in local movements and behavior of caribou, although such responses to structures and human activities were highly variable. For example, one group ran from a truck $500 \mathrm{~m}$ away, whereas other groups frequently approached and even crossed the road when several vehicles passed by. Most groups encountering elevated pipelines hesitated for a few seconds and then quickly trotted underneath to the other side.

Under some conditions, caribou appeared to benefit from the presence of the drilling structures, particularly during periods of oestrid fly harassment. Individual caribou were observed to stand for long periods under the pipelines or buildings. Standing for long periods of time is a common reaction to oestrid fly harassment (White et al., 1975). Many caribou also walked or stood on the roads, but were usually scared away by vehicles. To determine if caribou were using drilling structures for insect relief more than would be expected, I calculated the mean distance to the nearest structure for groups on the drill site grid that were observed to stand at one location for longer than 10 minutes. I compared this distance to that calculated for the control grid after superimposing the roads, pipelines, and drill pads on the control area map in the same configuration. The mean distance for the drill site grid was only $24 \%$ of that calculated for the control grid ( $t$-test; $t=5.36 ; 72 \mathrm{df} ; \mathrm{P}<0.001$ ), suggesting that caribou sought out the drilling structures for relief from insects and/or heat stress. However, insect relief habitat is commonly available in the delta, and thus the net benefit of the structures to caribou is uncertain.

\section{Crossing Success}

The movement pattern of 99 groups that approached within $500 \mathrm{~m}$ of a road, pipeline, or drill pad was classified into one of three categories: 1) crossed the first structure approached; 2) detoured around the structure; or 3) reversed direction and left the grid. If a group split while within $500 \mathrm{~m}$ of a structure, the movement of each new group was determined. A large lake to the east of the grid (Fig. 1) appeared to funnel many groups onto the grid; consequently, most groups that attempted to detour around the east side of the grid were included in this analysis. A schematic diagram of the movement patterns of the groups included in this analysis is shown in Fig. 3. Combining the movement data from all directions of approach shows that $70: 7 \%$ of the groups crossed the first structure encountered, whereas $19.2 \%$ detoured around drill site 16 , and $10.1 \%$ of the groups reversed direction and left the grid. Several of the groups that detoured around drill site 16 appeared to alter their direction of movement when they were more than $2 \mathrm{~km}$ from the nearest structure.

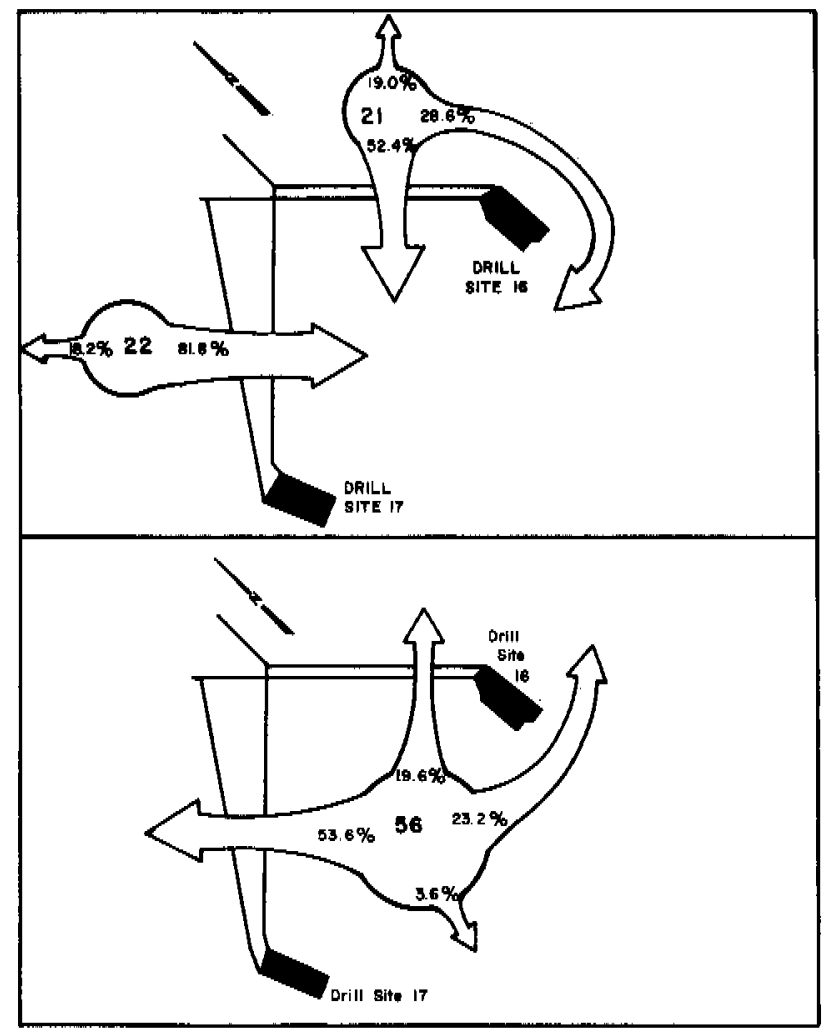

FIG. 3. Movements of 99 caribou groups that approached within $500 \mathrm{~m}$ of a road, pipeline or gravel drill pad, shown by their direction of approach. Only the first structure encountered was used in the analysis.

The movement patterns of groups on the control grid were similarly analyzed by artificially superimposing the same drilling structures on that grid in the same configuration. Considering the combined movements from all directions, $8.0 \%$ of the 87 groups detoured around the "structures", and $1.1 \%$ reversed direction and left the grid. If these values are used to adjust those determined for the drill site grid, approximately 
$20 \%$ of the groups altered their movements in response to the drilling operations.

\section{Calf Percentage}

The calf percentage has been used as an indicator of caribou responses to developments (Cameron and Whitten, 1979, 1980; Cameron et al., 1979). In 1980, the calf percentage calculated for the drill site grid using the same observation methods used in 1981 was $23.9 \%$, similar to the regional estimate of $21 \%$ for that year (Alaska Dept. Fish and Game, unpubl, data). In 1981 , calves comprised $10.5 \%$ and $12.5 \%$ of caribou observed on the control and drill site grids, respectively. This compares to the 1981 estimate of $28 \%$ for a much larger area of the herd's range (Cameron, pers. comm. 1982). The rate of vehicle traffic on the drill site grid during the last week of July (when the majority of caribou were observed on the grid in each year) in 1980 was almost twice that in 1981 . Both gravel drill pads were enlarged in 1980, and the levels of noise, construction, and other human activity were much higher than in 1981. In 1981, the only major change on the drill site grid was the presence of the elevated pipelines; however, these are not visible from the control site, and therefore, the presence of pipelines does not explain the low calf percentage in 1981 for the control grid.

These results can be explained either by annual variation in the use of the drainage, or possibly, by a learned avoidance of drilling operations by maternal cows. In the latter case, cows subjected to high levels of activity in 1980 may have avoided the area in 1981. However, cow/calf pairs observed in both 1980 and 1981 did not appear to avoid any portion of the grid. If the construction activity in 1980 caused cows to avoid the area the following year, it seems reasonable that they would also have avoided the area when construction was occurring. I therefore believe that the difference in the calf percentages was primarily the result of annual variation.

My study area was not typical of sites of drilling operations elsewhere within the oilfield, and my results must therefore be interpreted cautiously. The two drill sites in the Sagavanirktok River floodplain are at the eastern edge of, and across a large river channel from, the main Prudhoe Bay oilfield. Individual caribou that are sensitive to the structures and/or human activities are able to detour around the east side of the study area, and many groups did indeed detour around drill site 16 or reverse direction and leave the grid to the east. All pipelines in my study area were elevated approximately $2 \mathrm{~m}$ with the intention of providing for caribou passage, whereas in some areas of the main oilfield complex, pipelines are not. sufficiently elevated to allow physical passage of caribou. The petroleum industry and the Alaska Department of Fish and Game are continuing studies to determine road and pipeline designs that optimize caribou passage.

\section{ACKNOWLEDGEMENTS}

This research was conducted under a contract to the Prudhoe Bay Unit owners. The preparation of this manuscript was funded by LGL Alaska Research Associates. Field observations were recorded by myself, Dave Yokel, Amy Reges, Declan Troy, Rick Douglass, Slader Buck, and Betsy Sturm. The figures were drafted by Betsy Sturm. I wish to thank all of these biologists for their contributions to the study. I also wish to thank Dr. Don Keene of Arco Alaska for his assistance with many phases of this research.

\section{REFERENCES}

ALTMANN, J. 1974. Observational study of behavior: sampling methods. Behaviour 49:227-265.

CAMERON, R.D. and WHITTEN, K.R. 1979. Seasonal movements and sexual segregation of caribou determined by aerial survey. Journal of Wildlife Management 43:626-633.

1980. Influence of the Trans-Alaska Pipeline corridor on the local distribution of caribou. In: Reimers, E., Gaare, E. and Skjenneberg, S. (eds.). Proceedings of the Second International Reindeer/Caribou Symposium, Sept. 1979, Roros, Norway. 475-484.

SMITH, W.T. and ROBY, D.D. 1979. Caribou distribution and group composition associated with construction of the Trans-Alaska Pipeline. Canadian Field-Naturalist 93:155-162.

CHILD, K.N. 1974. Reaction of caribou to various types of simulated pipelines at Prudhoe Bay, Alaska. In: The Behavior of Ungulates and its Relation to Management. Morges, Switzerland: IUCN, 805-812.

ROBY, D.D. 1978. Behavioral patterns of barren-ground caribou of the Central Arctic herd adjacent to the Trans-Alaska Pipeline. Unpublished M.S. thesis, University of Alaska, Fairbanks, 200 p.

SOKAL, R.R. and ROHLF, F.J. 1969. Biometry. San Francisco: W.H. Freeman \& Co. 776 p.

WHITE, R.G., THOMSON, B.R., SKOGLAND, T., PERSON, S.J., RUSSELL, D.E., HOLLEMAN, D.F. and LUICK, J.R. 1975. Ecology of caribou at Prudhoe Bay, Alaska. Biological Papers of the University of Alaska, Special Rept. No. 2:151-201. 